\title{
Breast Cancer: A Public Health Issue that is also Subject of Social Construction
}

ISSN: 2637-773X

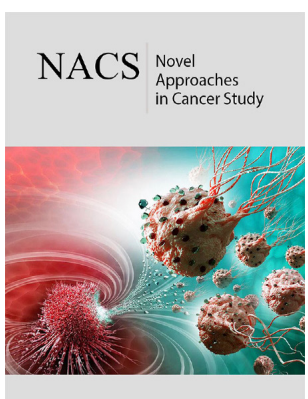

*Corresponding author: Carolina Santamaría Ulloa, Instituto de Investigaciones en Salud, Costa Rica

Submission: 湝 July 24, 2020

Published: 温August 28, 2020

Volume 5 - Issue 1

How to cite this article: Carolina Santamaría Ulloa. Breast Cancer: A Public Health Issue that is also Subject of Social Construction. Nov Appro in Can Study. 5(1). NACS.000605. 2020. DOI: 10.31031/NACS.2020.05.000605

Copyright@ Carolina Santamaría Ulloa, This article is distributed under the terms of the Creative Commons Attribution 4.0 International License, which permits unrestricted use and redistribution provided that the original author and source are credited.

\section{Carolina Santamaría Ulloa*}

Instituto de Investigaciones en Salud, Costa Rica

\begin{abstract}
Breast cancer claims thousands of lives all over the world every year. A historical perspective on the social construction of breast cancer policy is presented. This mini review examines breast cancer through a historical lens to provide evidence of how, through a dynamic process of social construction, different social actors constructed breast cancer into a public health issue that merits policymakers' attention.
\end{abstract}

Keywords: Breast neoplasms; Social construction; Public health

\section{Introduction}

Breast cancer is the most frequently diagnosed cancer and cause of death among women. Worldwide, the highest breast cancer incidence rates occur in North America and Western Europe, whereas the lowest rates are reported in East Asia and Middle Africa [1]. In the Americas, the highest incidence rates are observed in the United States and in some countries of South America such as Brazil and Colombia (Figure 1). Although the incidence has been rising in most areas of the world, mortality rates have been declining since the late 1980s in a number of more developed countries (Figure 2) mainly due to improvements in early detection and treatment [2].

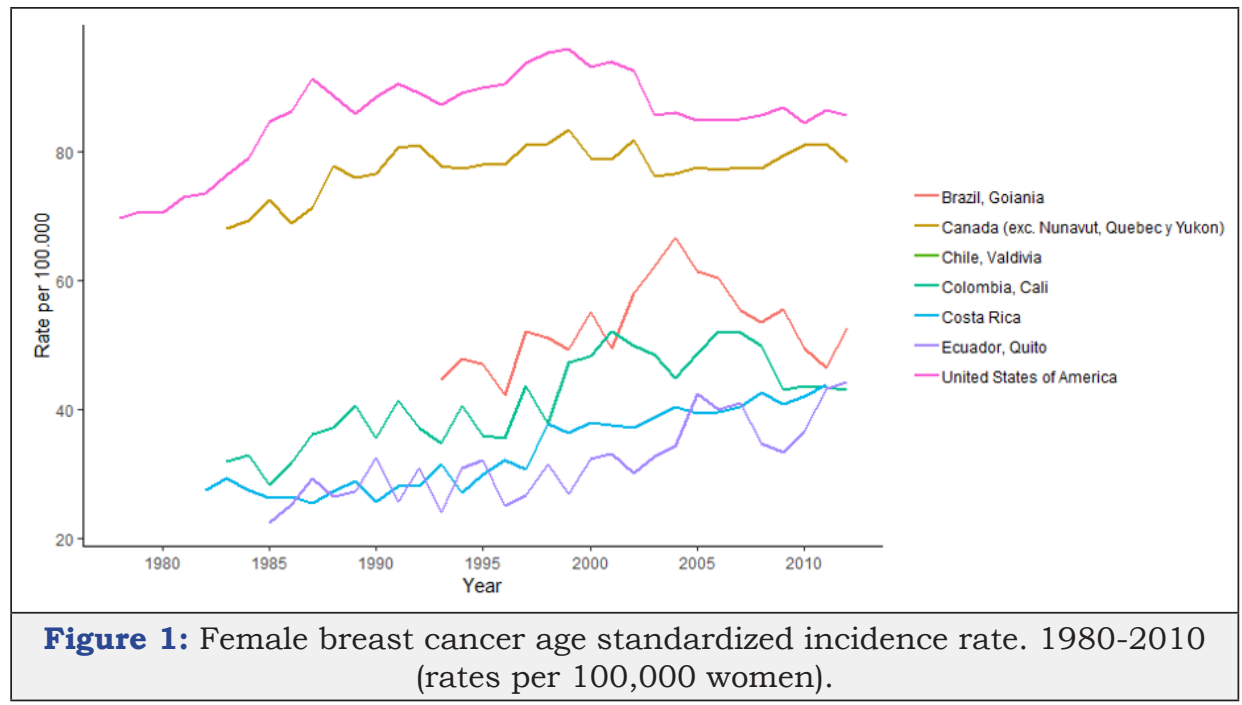

Source: Own elaboration based on IARC, 2019. 


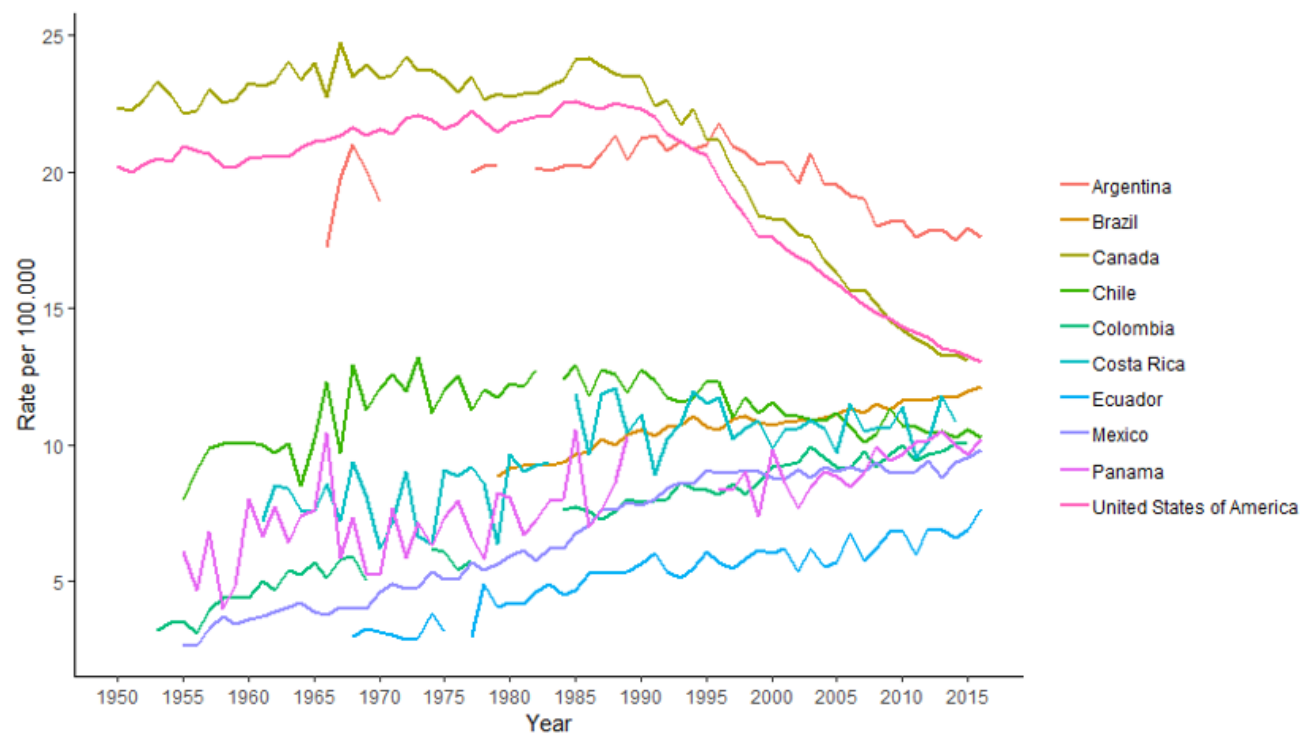

Figure 2: Mortality female breast cancer age standardized rate. 1950-2016 (rates per 100,000 women).

Source: Own elaboration based on IARC, 2019.

For cancer of the breast, and most other cancer sites, causes are only partially understood [3]. Four broad causes of breast cancer have been described in the epidemiological literature: reproductive risk factors, genetics, diet, and the environment. Reproductive risk factors include young age at menarche, late or no childbearing, lack of breast feeding, and older age at menopause. Regarding genetics, it is estimated that inherited mutations in BRCA1 and BRCA2 genes account for less than $5 \%$ of all cases. A western diet, low intake of fiber and high alcohol consumption are also considered risk factors. In the etiology of breast cancer, the environment plays a very important role. Radiation, particularly during breast development is recognized to cause breast cancer. There is also evidence that links certain pesticides to breast cancer [2].

Social construction of a health condition is a dynamic process through which the understanding of a health outcome is influenced by social discourse (i.e. the different communication mechanisms that occur within society). Social constructions are collective interpretations of public issues; they reflect the values that a society considers to be important over time [4]. Although social construction has been largely invisible for health science professionals, both popular and biomedical discourses have shaped our cultural understanding of breast cancer [5,6]. Historical developments in breast cancer treatment and economic resources dedicated to research, for example, have been partially influenced by the social discourse of health social movements. The intersection between public health science and social science becomes relevant when trying to disentangle the reasons why an issue initially relevant at the individual scale, becomes an important policy issue in western societies.

In exploring how policy is socially constructed we are investigating how social forces shape our understanding of health and which actions we as a society take towards health and illness. Our social understanding of breast cancer is shaped not only by science and the healthcare system, but also by the economy and by the influence of the social media. Policy decision making is significantly influenced by the social factors that define how the disease is understood and interpreted $[7,8]$. One way to understand the social construction of breast cancer policy is to look at the changing meanings for its cure. In 1894 William Halsted published on the use of radical mastectomy for a breast cancer cure [9]. In the 19th and early 20th centuries, it was thought that radical mastectomy was the cure for breast cancer. As early as 1910 many western nations began public health campaigns to control cancer. Radical mastectomy surgery was considered valuable by society and by medical doctors. The message delivered to women was that they needed to examine themselves and report breast lumps. In cases where a breast cancer was diagnosed, a radical mastectomy would be practiced. Females had to subjugate their concerns of appearance and sexuality in order to improve their chances of survival. By the 1950s, although it had become standard treatment, a women's frustration and anger resulted in radical mastectomy falling into disrepute $[5,10]$. Despite this frustration and anger, less radical, more conservative surgery options were slow to be tested [11]. In the 1960s, during the post-war era following the Second World War, after the realization that breast cancer had a systemic rather than a local nature, chemotherapy was introduced as an adjuvant [5].

By the late 1970s, research studies showed mastectomy was not curing advanced cancers, and breast cancer death rates were not decreasing. This contributed to a major paradigmatic shift related to the treatment for breast cancer. Epidemiological evidence from randomized trials demonstrated that, as compared to breastconserving surgeries accompanied by radiotherapy, survival following radical mastectomy was not significantly different. Mastectomy was not any more curative than other procedures and it did not prolong survival [12]. It was under the context of changing notions of gender and the new scientific knowledge that newly empowered women started demanding less invasive treatment 
options [10]. Therefore, the rigorous clinical trials and the social context in which they unfolded produced that radical mastectomy reduced [10].

In the $1980 \mathrm{~s}$ most of research investment went into mammography as a diagnostic tool [5]. The development of mammography resulted in an increase in the incidence rate especially in developed countries (Figure 1) [13]. This increase in the number of diagnosed women who sought treatment brought about the issue of not having scientific evidence on treatment effectiveness. In the 1990s, policymaking on breast cancer increased significantly. Policymaking resulted from increasing advocacy around breast cancer. Advocacy was a result of increased public awareness that was primarily spurred by an upsurge in scientific knowledge. Increasing numbers of women diagnosed with breast cancer started lobbying on their behalf. What was previously considered a private illness was now a public issue [6] Breast cancer was successfully framed as an imminent physical threat that could lead to death, and as an imminent symbolic threat that could jeopardize motherhood and eroticism [6].

Health Social Movements (HSMs) are an important political force concerning healthcare access, health inequality and illness experiences within broader social change [14]. The social context of breast cancer has changed over time and HSMs have contributed to this change. Women moved from private support groups to public advocacy efforts, like the women's health movement (WHM) and the breast cancer movement (BCM) in the United States. Breast cancer advocacy groups attracted media and social attention and they influenced policymaking [15]. WHM can be traced back to the 1970s and BCM to the early 1990s. BCM is in part responsible for policymaking to eradicate radical mastectomy. The importance of advocacy groups in the social construction of breast cancer policy especially during the 1990 s can be summarized as the delivery of the overarching message that breast cancer was a complex and growing public issue that required immediate government attention [6].

Breast cancer used to be framed as a personal issue each woman had to face individually, on which governmental responses were limited. Policy actors, including advocacy groups made visible the image of an illness that could potentially affect any woman. As an outcome of a social construction process, which included scientific evidence on screening and treatment options, breast cancer gained in terms of research funding, improvement of screening guidelines and more treatment options in western countries, especially in the developed ones. Nonetheless, mortality has not shown a clear-cut decline in developing countries, which raises questions about the unequal distribution of benefits from these socially constructed policies, and whether there are opportunities to reduce breast cancer mortality in developing countries.

\section{Funding Statement}

This research has been funded by the Vicerrectoría de Investigación, Universidad de Costa Rica, San José, Costa Rica.

\section{Conflicts of Interest}

The author declares no conflicts of interest. The author declares to have no personal, scientific, commercial or financial relationship with individuals or institutions that may bias the results presented in this material.

\section{Declaration of Responsibility}

Any points of view expressed in this material are those of the author alone and do not necessarily represent the official views of the Universidad de Costa Rica.

\section{References}

1. Shrestha DA, Dinesh N, Peter V, Per K (2018) Cervical cancer prevalence, incidence, and mortality in low- and middle-income countries: A Systematic Review. Asian Pac J cancer 19(2): 319-324.

2. WHO (2014) International Agency for Research on Cancer? World Cancer Report 2017. World Health Organization (IARC/WHO, Geneva, Switzerland.

3. Peters GH (1982) Breast cancer: Varied perceptions of social support in the illness experience. Soc Sci Med 16(4): 483-491.

4. Berger P, Thomas L (1966) The social construction of reality. A Treatise in the Society of Knowledge, Garden city, Anchor Books, New York, USA,

5. Thorne SE, Murray C (2000) Social constructions of breast cancer. Health Care for Women International 21(3): 141-159.

6. Martinez J (2000) The social construction of breast and prostate cancer policy. A Dissertation submitted to the Florida Atlantic University in partial fulfillment of the requirements for the degree of Doctor of Philosophy, Florida Atlantic University Boca Raton, Florida, USA.

7. Lerner B (2000) Inventing a curable disease: Historical perspectives on breast cancer. In: Kasper AS, Ferguson SJ (Eds.), Breast Cancer. Society shapes an epidemic. St. Martin's Press, New York, USA.

8. Carlsson M (2000) Cancer patients seeking information from sources outside the health care system. Support Care Cancer 8(6): 453-457.

9. Halsted W (1894) The results of operations for the cure of cancer of the breast at the Johs Hopkins Hospital from June 1889 to January 1894. Ann Surg 20(5): 497-555.

10. Kasper AaFS (2000) Conclusion. In Eliminating breast cancer from our future Breast Cancer. In: Kasper AS, Ferguson SJ (Editors.), Society shapes an epidemic. St. Martin's Press, New York, USA.

11. Henderson I (1995) Paradigmatic shifts in the management of breast cancer. New England Journal of Medicine 332(14): 951-952.

12. Jacobson JA, David ND, Kenneth HC, Teresa A, Seth M, et al. (1995) Tenyear results of a comparison of conservation with masectomy in the treatment of stage I and Stage II breast cancer. New England Journal of Medicine 332: 907-9011.

13. Wun LM, Feuer EJ, Miller BA (1995) Are increases in mammographic screening still a valid explanation for trend in breast cancer incidence in the United States? Cancer Causes and Control 6(2): 135-144.

14. Brown P, Zavestoski S, McCormick S, Mayer B, Morello-Frosch, et al. (2004) Embodied health movements: New approaches to social movements in health. Sociology of Health and Illness 26(1): 50-80.

15. Weissman C (2000) Breast cancer policymaking. In breast cancer In: Kasper AS, Ferguson SJ (Editors.), Society shapes an epidemic. St. Martin's Press, New York, USA. 